\title{
Laurencio en La Dorotea: ductilidad e hibridez al servicio de la acción en prosa
}

\author{
Laurencio in La Dorotea: Ductility and Hybrid in the Construction of the Action in Prose
}

Silvia López D'Amato

Universidad de Buenos Aires. Universidad Nacional Arturo Jauretche, Argentina

\section{Resumen:}

La Dorotea de Lope de Vega se caracteriza por concitar la atención de estudios provenientes de los más diversos enfoques críticos; objeto de debate, de análisis y de polémicas, la obra del Fénix se resiste a clasificaciones determinantes y se rebela ante categorizaciones conclusivas esgrimiendo una matriz estructural que integra teatralidad, autobiografía, poesía y tradición celestinesca. En esta ocasión nos detendremos en el personaje de Laurencio, en la construcción de los roles que desempeña, en las relaciones que entabla con los personajes de Don Bela y Gerarda y en las funciones dramáticas que le fueron asignadas.

Palabras clave: Ductilidad, Hibridez, Acción en prosa.

\section{Aвstract:}

La Dorotea of Lope de Vega is characterized by focus attention on studies from the most diverse critical approaches; under discussion, analysis and polemics, the work of the Fenix resists determinants classifications and rebels against conclusive categorizations brandishing a structural matrix that integrates theatricality, autobiography-memoirs, poetry and celestinesca tradition. This time we will stop at the character Laurencio, in the construction of the roles played, in the relationships that engages with the characters of Don Bela and Gerarda and the dramatic roles that were assigned to him.

KeYworDs: Ductility, Hybrid, Prose action.

La Dorotea de Lope de Vega se caracteriza por concitar la atención de estudios provenientes de los más diversos enfoques críticos; objeto de debate, de análisis y de polémicas, la obra del Fénix se resiste a clasificaciones determinantes y se rebela ante categorizaciones conclusivas esgrimiendo una matriz estructural que integra teatralidad, autobiografía, poesía y tradición celestinesca.

Carlos Brito Díaz (2003:12) considera que "La Dorotea es una pieza deliberadamente indefinida: en ella desembocan todos los géneros, todos los tonos, todos los disfraces, todas las estrategias y todas las constantes de su autor." Es, justamente, en esa deliberada indefinición donde se instala la dificultad para relacionar, de manera directa, personajes y funciones respecto de paradigmas literarios consolidados por la tradición genérica.

En esta ocasión nos detendremos en la configuración del personaje de Laurencio, en las relaciones que entabla con los personajes de Don Bela y Gerarda y en los roles determinados por las funciones dramáticas que le fueron asignadas.

Nuestro trabajo apela a la dimensión dramática de la obra; es por eso que en lo concerniente al análisis de los lineamientos expuestos hemos tomado como marco teórico los conceptos desarrollados por Anne Ubersfeld en su Semiótica teatral (1989).

En la configuración del personaje de Laurencio, ni sus características ni sus acciones parecen aceptar encasillamientos regidos por estereotipos preexistentes; el personaje se construye en la hibridez que proporciona la mutabilidad de los roles de criado/amigo de Don Bela. La dualidad amo-criado no sólo sirve para delimitar las funciones dramáticas de cada uno de ellos sino explica, además, los desplazamientos de Laurencio que van desde sobrellevar y organizar la comicidad -en relación directa con Gerarda y las cuestiones propias de la tercería - hasta los momentos finales cuando asume la tarea de anunciar la muerte de su señor; de este modo, la plurifuncionalidad del personaje impide que el estereotipo del criado se apropie de él confinándolo a un único rol.

Si bien Lope recurre a un tipo de personaje portador de funciones más o menos ritualizadas y de fácil reconocimiento dentro del modelo de la comedia, en La Dorotea, Laurencio comporta rasgos que lo acercan, 
también, a la tradición celestinesca. En palabras de José Manuel Blecua (2013:58) "Laurencio, el criado de Don Bela, presenta ciertas coincidencias con Pármeno, aunque Laurencio es forzosamente (como Gerarda) un personaje del siglo XVII".

El análisis de un reducido de número de microsecuencias en las que intervienen los personajes implicados en las relaciones de tercería (Laurencio/Gerarda/Don Bela) nos permitirá observar las configuraciones que desplazan a Laurencio de su rol de criado para reconfigurarlo al servicio de su inserción y funcionalidad en el entramado de la acción en prosa. A ese fin, se tomarán las conceptualizaciones de Anne Ubersfeld (1989:81) "rol en el sentido de función [...] en el sentido con que lo usa Greimas: actor codificado limitado por una función determinada. [...] el rol es una de las mediaciones que permite pasar de un "código" actancial abstracto a las determinaciones concretas del texto."

Laurencio aparece en tres de los cinco actos que conforman la obra -segundo, tercero y quintodesempeñando, en cada uno de ellos, roles diferentes:

La Escena Primera del Acto II presenta la fórmula modélica alcahuete-pretendiente-criado; la relación Gerarda-Don Bela se construye en la tensión entre el deseo masculino de conquistar a Dorotea y la ambición femenina de obtener el mayor éxito posible en el arte de la sonsaca. La escena completa se sustenta en las estrategias que impone la tercería; la contienda entre el dar y el recibir será la fuerza motriz de las acciones dramáticas.

Las intervenciones de Laurencio, en su rol de criado, intentan revelar -sin éxito- el engaño que su amo no advierte. El diálogo concluye con la participación del enamorado:

BELA: Ya es tarde para persuadirme. Sirve y calla, Laurencio, que no te traje para consejero, sino para criado. $(88)^{1}$

El parlamento refleja la pertenencia social de los personajes y delimita los roles codificados por funciones claramente determinadas. La voz del amo adopta un tono imperativo que consolida la relación asimétrica amo-criado y obliga a Laurencio a acatar la orden recibida.

La intervención de los criados en los amores de sus amos es frecuente en las obras con matriz celestinesca; no obstante, en La Dorotea, Laurencio se aleja del prototipo que busca sacar provecho de su amo (Sempronio/ Calisto) y se ubica en las proximidades del criado confidencial que, en clave paródica, procura -sin lograrloproteger al indiano enriquecido de los artilugios que emplea la alcahueta para desplumarlo.

En la Escena Quinta del mismo Acto, Laurencio ratifica sus funciones de criado al reprocharle a su amo "gastar con desperdicio lo que adquirió con trabajo"; nos encontramos ante un servidor fiel y preocupado que se muestra celoso no de los amores de Don Bela -como lo sugiere la criada Celia- sino de su hacienda (128).

En ambas escenas, Laurencio aporta la cuota de comicidad predeterminada por una convención dramática que, en palabras de Félix Monge (1957:71) “embadurna a todos los personajes” y que a su vez, se nutre de rasgos heredados de la tradición celestinesca; hilaridad que desatiende el decoro para acentuar el contraste entre las sutilezas del humor cortesano y la vulgaridad de la risa vinculada a las clases menos privilegiadas: formula descripciones degradantes de la vieja que conllevan un alto valor satírico y no escatima invectivas respecto de la profesión que ella ejerce. El decir y el hacer de Laurencio ponen de relieve la contracara de las acciones de Don Bela quebrantando el discurso poético del amo enamorado. Las críticas a la ingenuidad del pretendiente, la defensa de los intereses del señor comienzan a desajustar el modelo de criado cristalizado tanto por la comedia como por la tradición celestinesca.

En la Escena Quinta del Acto III, Don Bela y Laurencio pasean por la calle donde vive Dorotea; la descripción espacial -calle/casa/reja- sirve de telón de fondo para las confesiones del indiano respecto de los sentimientos que lo unen a la mujer deseada y de todo lo que está dispuesto a ceder para conquistarla. El diálogo entre amo y criado discurre por dos dimensiones: por un lado, el enamorado insiste en exaltar las virtudes y bondades de aquella que cautivó su alma ("hermosa, con gracia natural, limpia") y por el otro, Laurencio reafirma los perjuicios enraizados en ese amor no correspondido (Fernando, ha vuelto a Madrid dispuesto a restablecer su relación con Dorotea). La escena finaliza con el siguiente diálogo: 
BELA: Paréceme que vienes esta noche de mala gana: vuélvete, Laurencio, que estás impertinente.

LAURENCIO: No podré obedecerte, que no es justo que te deje solo.

BELA: Pues si has de estar conmigo, calla.

LAURENCIO: Mal hice en hablar como amigo, habiendo de callar como criado. (219)

En consonancia con la escena anterior, las distancias que separan el vínculo amo/criado vuelven a acortarse. Laurencio no acepta la orden de su amo y éste solo impone el silencio como la condición que sostiene, débilmente, los roles establecidos. Desde el punto de vista lingüístico, el personaje es el sujeto de la enunciación cuyo discurso lo constituye en eso que su enunciado manifiesta; Laurencio cumple las funciones de un amigo que cuestiona los medios utilizados para alcanzar los favores de Dorotea ("oro y Gerarda"), que discute las diferencias entre los conceptos de posesión y propiedad (“¿Pues qué propiedad es la tuya en lo que posees con mala fe?") y que trata de convencer al indiano enamorado de que "ni todo el oro ni quitar del mundo a una embustera" es el remedio adecuado para curar las heridas que el amor no correspondido provoca.

El desplazamiento criado/amigo procura la complementariedad, supone dos perspectivas para considerar una misma realidad; la visión del universo circundante que uno y otro representan responden a las funciones adquiridas y serán ellas las que reorganizarán el conflicto dramático.

La dupla amo-criado/amigo no vuelve a aparecer hasta la primera escena del quinto Acto. Don Bela comparte con Laurencio la tristeza que le provoca el desamor de Dorotea y el terror de sentirse aborrecido por ella:

BELA: Después que te pasé de criado a amigo, has perdido la condición de los que sirven, que parlan cuanto saben. Pero pues ya eres amigo, como tienes licencia de reprehenderme, tenla de desengañarme. (337)

$[\ldots]$

BELA: Pues desa manera, ¿qué me queréis, tristezas? ¿Qué me afligís, celos? Laurencio es mi criado y mi amigo, y por la una parte no parla y por la otra no desengaña... (337)

La implicación de los roles criado-amigo debilita los encasillamientos. Si el modelo de inserción al que responde el criado es el de ayudante de un sujeto que intenta alcanzar un determinado objetivo; en este caso, es el mismo Don Bela el que recurre a su amigo para que desarrolle las funciones de oponente en la insistencia de alcanzar un amor no correspondido y, al mismo tiempo, para que lo ayude a lograr otro objetivo: asumir el desengaño. El apelativo adjudicado a Laurencio iconiza textualmente el rol que lo habilita a actuar en un plano personal e íntimo y le otorga al personaje un nuevo decoro que lo ubica en un estamento superior, en una relación simétrica respecto de quien fuera su amo. Es el criado devenido en amigo el que aporta paliativos a los pesares de Don Bela:

LAURENCIO: No te entristezcas, por Dios; que no estás en mal estado de enmendarte, pues lo conoces. A buen tiempo viene Gerarda: ella te desenfadará con sus vejeces y aun con sus astucias. (340)

La escena siguiente presenta nuevamente la tríada alcahueta/pretendiente/amigo-criado; el diálogo entre los personajes podría organizarse en dos momentos que se articulan en la variable presencia/ausencia de Don Bela.

En presencia de Don Bela, Laurencio recupera la comicidad inherente a su condición de criado remarcando, a través de la comicidad satírica, las características distintivas de Gerarda: hechicera, aficionada al vino, célebre en embustes y eximia en el arte de la sonsaca; en relación con Don Bela repite las críticas a su generosidad y es el encargado - muy a su pesar- de entregar los 26 reales que reclama la alcahueta por los servicios prestados.

En ausencia de Don Bela (“me voy a misa”), Laurencio adquiere mayor protagonismo y ocupa espacios reservados a su amo; se muestra interesado en los negocios de Gerarda y acepta -aunque con algunos reparoslos servicios que le ofrece la vieja meretriz: 
GERARDA: Pues algo has de hacer tú: llégamelos a treinta, y te daré diez y siete años sin afeites, sin pedir, sin malicia, y con una cara como una manzana de Nájara. (345)

Si bien la figura del dinero circula constantemente en la relación Don Bela-Dorotea, las gestiones de Gerarda intentan disimular las evidencias; aunque detrás del velo de las apariencias los temas amorosos quedan subordinados al propósito netamente mercantil de la tercería, un negocio que Don Bela acepta sin cuestionamientos porque el fin justifica los medios y porque lograr el amor de la mujer deseada no tiene precios ni valores que no se puedan negociar. En cambio, el quehacer de la alcahueta genera en Laurencio interrogantes que exceden el marco de la venalidad:

LAURENCIO: Dame pena que sea casada esa moza.

$[\ldots]$

LAURENCIO: ¿Y si me enamoro?

$[\ldots]$

LAURENCIO: Siempre tuve respeto al matrimonio.

$[\ldots]$

LAURENCIO: Hojea tu catálogo y mira a cuántas hojas está alguna desocupada de riesgos, humilde de rostro, novicia de semblante y sobre bisoña de pedir, diestra de guardar decoro. (346)

El desajuste entre la clave burlesca en la que se desarrolla el vínculo alcahueta-criado y la seriedad que imprime Laurencio al expresar sus sentimientos subvierte el comportamiento de la axiología dominante; los reparos de Laurencio ponen en tela de juicio los valores de los estamentos privilegiados. De este modo, al situar a Laurencio en un espacio dramático serio, Lope deja en claro que el carácter paródico que va irremediablemente unido al rol del criado no es la única marca del personaje.

Dado que todo discurso teatral conlleva un doble sujeto de enunciación, se podría pensar que en las palabras de Laurencio resuenan las reflexiones del autor acerca de las relaciones amorosas y su repudio a un sistema ético-moral que conduce a la decadencia, a la hipocresía y a la inmoralidad.

Las negociaciones Laurencio-Gerarda continúan; el hombre se muestra arrepentido ("si no te hubiera dado los cuatro reales, no te los diera"); la mujer se muestra afectada y redobla el desafío:

GERARDA: Laurencio, poco a poco, que también hay de mi oficio entre vosotros.

LAURENCIO: El que sirve no es tercero, sino criado. (347)

Laurencio se construye en la epifanía de una serie variada y polivalente de rasgos que lo caracterizan en un dinámico proceso de codificación y decodificación pero excluye explícitamente aquellos que involucran a su clase en los negocios espurios de la tercería.

La escena finaliza con las concepciones que cada interlocutor tiene acerca del rol desempeñado por el otro; en ambos casos, se emplean comparaciones en tanto procedimiento retórico frecuente en el discurso satírico que sirve para degradar y deshumanizar alguno de los términos que intervienen en la comparación (criado/ perros; terceros/ochos y nueves en la baraja).

GERARDA: Porque los criados como tú son como los perros, que muerden a los pobres porque piensan que les vienen a quitar lo que les toca a ellos. A fe que no te me atrevías tú cuando me había menester don Bela. (349)

La simbología positiva del segundo término de la comparación ("perro") asociada a la fidelidad, a la amistad, a la inteligencia, a la protección en boca de Gerarda adopta valoraciones opuestas; se reduce a la mezquindad, al egoísmo y a la falta de consideración hacia esos otros que están destinados a la marginalidad. Asimismo, la respuesta de Laurencio propone otra comparación degradante:

LAURENCIO: También quiero que sepas que los terceros son como los ochos y nueves, que vienen atados y iguales en la baraja, y en queriendo jugar, los echan en la calle. (349) 
La comparación cosificadora quita todo rasgo humano a aquellos que practican la tercería; los vuelve desechables, prescindibles, inoperantes. Juan Manuel Rozas $(1990,133)$ estudia este momento de la obra y lo asocia con el enfrentamiento personal y literario que el Fénix mantuvo a lo largo de su vida y de su obra con Pellicer. El investigador sostiene que "no se trata de una situación anecdótica ni pasajera, sino una idea absorbente que condicionará hasta la visión del mundo de Lope, en ciertos aspectos, en el último lustro de su vida”.

A lo largo del último Acto, la obra va adquiriendo evidentes tonos moralizantes cargados de una triste admonición: las reflexiones de Laurencio acerca de los vínculos amorosos, la desilusión tanto de Dorotea como de Fernando por sus amores frustrados, las muertes de Gerarda y de Don Bela como una suerte de escarmiento y advertencia; palabras y acciones, personajes y roles que cumplen lo que Lope, bajo la máscara de Francisco López de Aguilar, anuncia en el Prólogo de la obra "conozcan los que aman con el apetito y no con la razón, qué fin tiene la vanidad de sus deleites y la vilísima ocupación de sus engaños" (8).

Brito Díaz (2003:116) sostiene que en La Dorotea "ni Don Bela encaja en el molde del galán, Dorotea tampoco encarna a la dama convencional ni los subordinados aquí responden a los criados estereotipados en la escena"; siguiendo esta afirmación hemos intentado estudiar la configuración/desfiguración del personaje de Laurencio a través del análisis pragmático de algunas microsecuencias y de los personajes que inciden en las funciones dramáticas que le fueron asignadas; ello nos permitió observar desplazamientos y mudanzas que hacen de Laurencio una criatura escénica maleable cuya ductilidad e hibridez operan al servicio de la acción en prosa.

\section{BiBLIOGRAFÍA}

Brito Díaz, Carlos, 2003. "Lope en Lope: los palimpsestos del Fénix en su propia escritura (La Dorotea)", La Perinola, 7, 103-121.

Copello, Fernando, 2001. "La Dorotea como género abierto" en La Dorotea de Lope de Vega, Monique Guell (dir.), París: Ellipse, 37-51.

Hermenegildo, Alfredo, 1994. "Funciones dramáticas del personaje ancilar", Criticón, 60, 77-92.

Monge, Félix, 1957. "La Dorotea de Lope de Vega”, Vox Romanica, 16, 60-145.

Rozas, Juan Manuel, 1990. “Lope contra Pellicer (historia de una guerra literaria)”, Estudios sobre Lope de Vega, Madrid: Cátedra, 133-168.

Ubersfeld, Anne, 1989. Semiótica teatral, Traducción de F. Torres Monreal,Madrid: Cátedra. (1ª ed.: 1977. Lire le Théatre, Paris: Éditions sociales.)

Vega, Lope de, 2011. La Dorotea, Edición de Donald McGrady, Madrid: Real Academia Española.

\section{Notas}

1. Todas las citas de La Dorotea fueron tomadas de la edición citada en la bibliografía. 